\title{
Editorial
}

\section{ACERCA DE LA ENSEÑANZA DE LA INVESTIGACIÓN JURÍDICA EN LOS PROGRAMAS DE MAESTRÍA EN LAS FACULTADES DE DERECHO EN COLOMBIA}

\author{
Juan Carlos Villalba Cuéllar (Editor) \\ Andrés González Serrano (Coeditor)
}

Hoy en día los índices de estudiantes graduados de los programas de maestría en Colombia son muy bajos y esto obedece a diversos factores, algunos atribuibles a los estudiantes, como la mala comprensión de lo que es una maestría, ya que en la mayoría de los casos no conocen realmente la finalidad de este tipo de programas, y piensan ligeramente que una maestría es una especialización larga. Aunque la verdadera diferencia entre una maestría y una especialización es el componente investigativo de la primera.

El estudiante de una maestría en el campo del derecho, además de los créditos obligatorios, debe cursar un componente de investigación, en el cual, a través del aprendizaje de métodos y metodología de la investigación jurídica (o sociojurídica) adquirirá competencias para el planteamiento y ejecución de su trabajo de grado. Ya sea que se trate de una maestría en profundización o investigación, para el caso colombiano, este requisito debe cumplirse.

Los estudiantes de maestrías en derecho en nuestro contexto no se están graduando en un porcentaje importante debido a la falta del cumplimiento del requisito denominado "trabajo de grado", y aunque ese resultado puede deberse a varios hechos, entre ellos la concepción distorsionada que tienen los estudiantes de la "investigación" como asignatura y sus verdaderas bondades (prejuicio que los jóvenes traen a veces del pregrado y los adultos padecen por el simple hecho de que nunca les enseñaron a investigar); parece que el programa o institución en donde se cursa la maestría tiene responsabilidad directa. Claramente muchos de los candidatos a magíster no se gradúan porque no les estamos enseñando bien a investigar para elaborar su trabajo de grado.
Sobre este punto queremos hacer una corta reflexión. Lo primero que hay que decir es que en la praxis colombiana, en materia de investigación, existen tantas metodologías y métodos como profesores pueden haber; es decir, no hay dos docentes de metodología que tengan el mismo discurso y conciban los métodos de igual modo. Esto que pudiera ser normal hablando de academia no es conveniente en materia de investigación formativa.

Dos factores pueden generarlo: nuestro derecho es importador neto de teorías y metodologías y métodos de investigación. Cada cual enseña la forma de investigar el derecho de acuerdo con el procedimiento extranjero que le hayan enseñado, y no falta aquel que a manera de dogma diga que ese método es el mejor y el único para investigar el derecho. Entonces se presentan situaciones como la siguiente: un grupo de estudiantes de maestría en primer semestre recibe clases de un profesor que enseña cierta forma de investigar, pero en segundo semestre, tercero o cuarto, viene otro profesor a hacer borrón y cuenta nueva para imponer su manera de investigar, que siempre será mejor que la del anterior docente, para desgracia de los estudiantes.

El resultado es palpable: estudiantes que no tienen ideas claras de metodología y métodos de investigación jurídica, y lo que resulta para ellos peor, están desorientados frente al abordaje que deben darle al trabajo de grado, lo cual de seguro echará al traste las posibilidades de grado del maestrando. ¿Cuál es el fondo del problema? Un país debería contar con directrices claras de cómo se investiga en materia jurídica. Es decir, una serie de pautas que determinen en la forma y en el fondo la esencia de la investigación en derecho. 
Expresamos esto porque en otros contextos jurídicos este problema parece mitigado en alto grado porque se ha decidido de antemano esa cuestión, por ejemplo, los anglosajones, los franceses y los alemanes tienen definido ese asunto, y valdría la pena que en Colombia dejáramos de hacer trasplantes burdos de la investigación que ellos hacen y crear una opción propia. Pero para ser realistas, lograr esto es muy complejo, y algunos dirán que es discutible su pertinencia, por lo tanto está lejos de ser una realidad.

Siendo más pragmáticos conviene entonces sugerir que por lo menos al interior de cada universidad o instituciones similares en donde se investigue el derecho, se fijen pautas acerca del método y metodología de una investigación jurídica en maestría. Esto equivale a institucionalizar la forma de investigar, que aunque parezca arbitraria, sí atenuará el riesgo de que la enseñanza de la metodología y los métodos de investigación queden al vaivén de las escuelas extranjeras a las que se afilian los investigadores que enseñan el derecho y muchas veces, a la necedad de algunos investigadores de imponer sus métodos como la verdad única en investigación.

Así las cosas, la institución impondrá unos criterios metodológicos y el método o métodos admitidos en la investigación que se haga al interior del programa de maestría, para seguridad de todos. El pragmatismo impera, y esto no afecta la calidad de la investigación, ya que el método y la metodología son herramientas para la investigación, pero el objeto de estudio que es el derecho permanece allíy debe ser abordado con rigor científico. Aclaramos que este planteamiento práctico lo consideramos válido para administrar programas de maestría en derecho, pero para contextos como el de la investigación científica que hacen los docentes investigadores y para el nivel de doctorado tiene otros matices e ingredientes que lo hacen más complejo.

Otra forma práctica de aminorar este riesgo para las maestrías de tener un bajo número de graduados a causa de la inadecuada enseñanza de la investigación, consiste en que el programa permita a un solo profesor asumir la enseñanza de la investigación y la tutoría metodológica de los trabajos de grado por cada cohorte, lo cual no siempre es fácil debido a la rotación del personal docente o a disponibilidad de este. Unas pautas institucionales como las que proponemos contrarrestan esos factores de riesgo. También ayudará que el profesor de investigación además de servir de guía metodológico sea afín al tema o temas objeto de investigación, pues tendrá más herramientas para orientar los trabajos de grado.

Otro elemento que parece importante es el grado de consciencia que tenga una institución sobre sus capacidades para el apoyo investigativo a los estudiantes de posgrados. Si los recursos educativos y el equipo docente calificado de apoyo a los estudiantes de la maestría no son suficientes o son limitados, se espera que el programa conforme grupos o cohortes razonablemente coherentes con esa capacidad, lo contrario es una irresponsabilidad y va a liquidar cualquier pretensión que tengan los docentes y quienes dirigen los programas de que los estudiantes hagan investigación de calidad y cumplan ese requisito para graduarse. La falta de tutores temáticos idóneos y disponibles para atender las dudas y corregir los avances de los estudiantes es evidente en muchos programas de maestría colombianos y es una queja constante de los maestrandos. Esto depende de que la facultad de derecho cuente con un centro de investigaciones sólido y un grupo de investigadores competente para acompañar a los estudiantes.

Se trata entonces de un asunto al que cada programa o universidad debe hacerle frente, y como se trata de investigación formativa las soluciones pragmáticas pueden ser útiles para generar coherencia y eficacia en la enseñanza de la investigación. Políticas y reglas claras acerca de los requisitos metodológicos de los trabajos de grado, responsabilidad por parte de la institución al conformar las cohortes y centros de investigación con recursos físicos y personal idóneo para acompañar la investigación permitirán que la calidad y los resultados de la investigación en maestría mejoren, así como los porcentajes de graduandos.

Algunas facultades de derecho y programas de maestría se están tomando a la ligera el tema de la enseñanza de la investigación y no se han dado cuenta que este factor puede llevar al fracaso sus propios programas. Esperamos que este panorama cambie pronto para que las maestrías en el campo del derecho cumplan su objetivo principal a cabalidad. 